\title{
Heat-shock positively modulates oxidative protection of salt and drought-stressed mustard (Brassica campestris L.) seedlings
}

\author{
Mohammad Anwar Hossain ${ }^{1,2^{*}}$, Mohammad Golam Mostofa ${ }^{1,3}$ and Masayuki Fujita ${ }^{1}$ \\ *Correspondence: hossainma@gmail.com \\ 'Laboratory of Plant Stress Responses, Department of Applied Biological Science, Faculty of Agriculture, Kagawa University, \\ Miki-cho, Kita-gun, Kagawa 761-0795, Japan. \\ ${ }^{2}$ Department of Genetics and Plant Breeding, Bangladesh Agricultural University, Mymensingh-2202, Bangladesh. \\ ${ }^{3}$ Department of Biochemistry, Bangabandhu Sheikh Mujibur Rahman Agricultural University, Gazipur-1706, Bangladesh.
}

\begin{abstract}
A large number of studies have shown the existence of cross-tolerance in plants, but the exact physiological and biochemical mechanism(s) is poorly understood. In this study, heat-shock $\left(42^{\circ} \mathrm{C}, 5 \mathrm{~h}\right)$ induced salinity and drought tolerance and possible involvement of antioxidative and glyoxalase systems were investigated in mustard (Brassica campestris L.) seedlings. Seven-day-old seedlings were subjected to salt ( $150 \mathrm{mM} \mathrm{NaCl}, 48 \mathrm{~h}$ ) and drought stress (induced by $20 \% \mathrm{PEG}, 48 \mathrm{~h}$ ) with or without heat pretreatment. Both salt and drought stresses led to a severe oxidative stress as indicated by profound increases in hydrogen peroxide $\left(\mathrm{H}_{2} \mathrm{O}_{2}\right)$ and malondialdehyde (MDA) levels. A significant increase in ascorbate (AsA) content was observed in response to drought stress but the glutathione (GSH) and glutathione disulfide (GSSG) contents increased in response to both salt and drought stress. The GSH/GSSG ratio decreased significantly in response to drought stress. Salt stress led to a significant increases of ascorbate peroxidase (APX), glutathione reductase (GR), glutathione $S$-transferases (GST) activities; whereas, catalase (CAT) and glyoxalase II (Gly II) activities decreased. Drought stress resulted in a significant increase in monodehydroascorbate reductase (MDHAR), dehydroascorbate reductase (DHAR), glutathione peroxidase (GPX) and glyoxalase I (Gly I) activities; whereas, CAT and Gly II activities decreased. Seedlings primed with heat-shock positively modulates the activities of APX, DHAR, GR, GST, GPX, CAT, Gly I and Gly II, and maintained lower levels of GSSG, $\mathrm{H}_{2} \mathrm{O}_{2}$ and MDA as compared to the control mostly also salt and drought-stressed seedlings. Our results showed that a retention of the imprint of previous stress exposure (heat-shock) protects the plants from salt and drought-induced oxidative stress by stimulation of antioxidative and glyoxalase defense systems.
\end{abstract}

Keywords: cross-tolerance, heat-shock, salt and drought stress, antioxidative and glyoxalase system, Brassica campestris L.

\section{Introduction}

Soil salinity and drought are the two most common abiotic stresses constraining crop growth and productivity [1]. Currently, more than 800 million ha of land is affected by salinity [2], and about $1 / 3$ of the world's arable land has experienced yield reduction due to cyclical or unpredictable drought [3]. Problems of salinity and drought get aggravated due to climate change [4]. As a result, the development of improved levels of tolerance to these stresses has become an urgent concern for many crop breeding programs to ensure global food security to an increasing world population. In parallel, much research effort is being applied to gain a better understanding of the complex adaptive mechanisms used by plants to combat abiotic stress [5], although we are far from complete understanding of this complexity [1]. Identification of key metabolic pathways, genes and proteins underlying abiotic stresses has thus become a priority in the research for improved crop stress tolerance [6-10]. A understanding of the regulation of these pathways and genes and their response to stress would provide opportunities for the manipulation of gene expression in crop plants [6].

Salt and drought stresses lead to oxidative stress in plant cell due to higher leakage of electrons towards $\mathrm{O}_{2}$ during photosynthetic and respiratory processes leading to enhancement of reactive oxygen species (ROS) and free radicals such as singlet oxygen $\left({ }^{\prime} \mathrm{O}_{2}\right)$, superoxide radicals $\left(\mathrm{O}_{2}^{-}{ }^{-}\right)$, hydrogen peroxide $\left(\mathrm{H}_{2} \mathrm{O}_{2}\right)$, and hydroxyl radicals ( $(\mathrm{OH})$ [11-12]. Methylglyoxal (MG), a cytotoxic compound, was also found to increase in response to various abiotic stresses [13-16]. An increase in MG level in plant cells further intensifies the production of ROS by inactivating the antioxidant enzymes [16-18] and interfering with photosynthesis [19]. This increase in ROS and MG exposes cells to oxidative stress leading to lipid peroxidation, chlorophyll destruction, biological macromolecule deterioration, membrane dismantling, ion leakage, and DNA-strand cleavage and finally death of plants $[7,9,16,20]$. To protect against oxidative stress, plant cells possess an extensive ROS scavenging network, which involves non-enzymatic antioxidants, including vitamin C, vitamin E, glutathione, carotenoids and flavonoids, as well as numerous enzymatic mechanisms such as multiple superoxide dismutases (SOD), ascorbate peroxidase (APX), monodehydroascorbate reductase (MDHAR), dehydroascorbate reductase (DHAR), glutathione reductase (GR), catalase (CAT), 


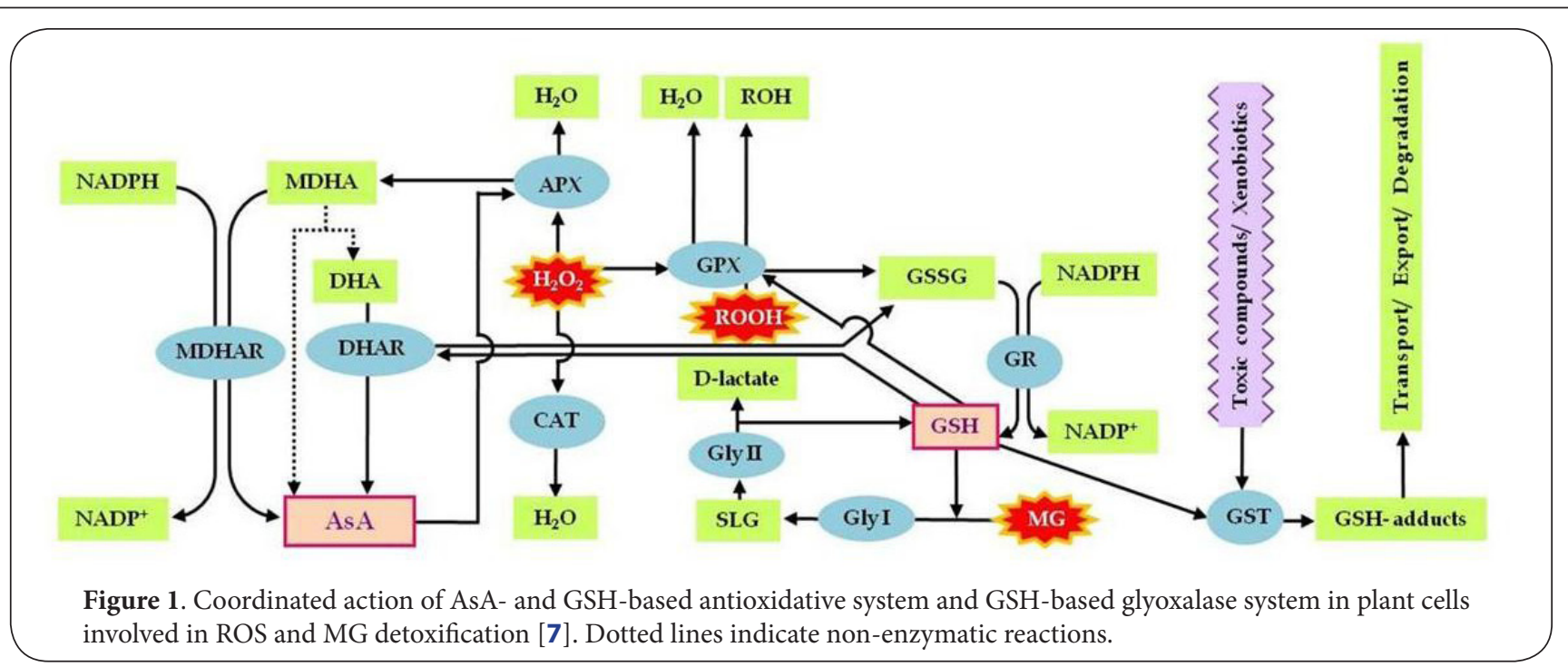

glutathione peroxidase (GPX), glutathione S-transferase (GST) [21]. Likewise, the glyoxalase system is an integral component and major pathway of cellular metabolism of cytotoxic MG, consists of two enzymes: glyoxalase I (Gly I) and glyoxalase II (Gly II). These enzymes act coordinately to convert MG and other 2-oxoaldehydes to their 2-hydroxyacids using GSH as a cofactor in a two-step reaction $[16,22]$. The overexpression of the glyoxalase pathway enzymes in transgenic tobacco and rice plants has been found to lower the levels of ROS and MG under stress conditions by maintaining GSH homeostasis [23-25]. Transgenic tobacco plants overexpressing both Gly I and Gly II genes also showed higher salinity tolerance by additional increase of GSH metabolizing enzyme (GST, GPX and GR) activities further denoting the close interaction between the antioxidant system and the glyoxalase system in imparting stress tolerance in plants $[7,16,23]$. The results of numerous recent studies have shown that the reduction of oxidative damage and increased resistance to abiotic stresses are often correlated with the more efficient regulation of both antioxidative and glyoxalase systems [Figure $1 ; 7,15,16,20$, 26-29].

Heat stress - high temperature- affects the metabolism and structure of plants, especially cell membrane and many basic physiological processes, such as photosynthesis, respiration, and water-relations [31-32]. Plant must cope with heat stress for survival, so they developed different mechanisms including the maintenance of cell membrane stability, capturing the ROS, synthesis of antioxidant, accumulation and osmoregulation of osmoticum, induction of transcription factor, accumulation of heat shock proteins (HSPs) [31-32]. The mechanism(s) of cross-adaptation is little known although a few hypotheses have been proposed to try to elucidate it; most are based on roles of $\mathrm{H}_{2} \mathrm{O}_{2}, \mathrm{GSH}, \mathrm{AsA}$ and $\mathrm{HSPs}$ [33-40]. Involvement of glutathione in heat shock- and hydrogen peroxide-induced cadmium (Cd) tolerance of rice (Oryza sativa L.) seedlings was reported by Chao et al., [36]. Later on, Chao and Kao [38] showed that heat-shock $\left(45^{\circ} \mathrm{C}, 3 \mathrm{~h}\right)$ induced AsA accumulation in leaves induces $\mathrm{Cd}$-induced oxidative stress tolerance of rice (Oryza sativa L.) seedlings. Heat-shock induced Cd-tolerance rice seedlings were also found to be associated with higher APX and GR activities [41]. Recently, Ferreira-Silva et al., [39] showed that high temperature positively modulates oxidative protection in salt-stressed cashew (Anacardium occidentale) plant by the activation of antioxidant enzymes such as SOD, APX, CAT as well as favorable changes in the ascorbate redox state. Additionally, few recent studies showed an increase in Gly I and II activities, Gly I gene and protein expression by heat stress [13,42-43] and efficient regulation both AsA and GSH contents and their utilizing and regenerating enzymes is an important predominant factor controlling ROS and MG levels to ensure abiotic stress tolerance $[15,26-29]$. However, it is unclear whether there is a cross-adaptation between heat, salt and drought stresses in Brassica and if there any involvement of antioxidative and glyoxalase defense systems. Additionally, there is no evidence showing that heat-shock induced salinity and drought tolerance is due to an efficient regulation of glyoxalase system and antioxidant defense system of plants. Considering the total aspect, the present study was therefore undertaken to explore the possible biochemical mechanisms of heat-shock induced salinity and drought tolerance. To our knowledge, these data represent the first evidence that heat pre-treatment enhances salt and drought stress-induced oxidative stress tolerance in mustard seedlings by stimulating the antioxidative and glyoxalase defense systems.

\section{Materials and methods}

Plant materials and growth conditions

Uniform size seeds of the selected mustard (Brassica campestris cv. Shampad) variety was surface-sterilized with $70 \%$ ethanol then washed several times with distilled water. The seeds were 
then soaked with distilled water for $15 \mathrm{~min}$ and sown in Petri dishes $(9 \mathrm{~cm})$ lined with 4 layers of filter paper moistened with $10 \mathrm{ml}$ of distilled water for germination under dark conditions for 3 days following the method of Hossain et al., [29]. Germinated seedlings were then grown in Petri dishes that contained 10,000-fold diluted Hyponex solution (Hyponex, Japan) under controlled conditions (light, $100 \mu \mathrm{mol}$ photon $\mathrm{m}^{-2} \mathrm{~s}^{-1}$; temp, $25 \pm 2^{\circ} \mathrm{C}$; RH, 65-70\%).

\section{Heat-shock pre-treatment and salt and drought stress treatments}

Seven-day-old seedlings of approximately equal sizes were employed for heat shock pre-treatment $\left(42^{\circ} \mathrm{C}\right.$ for $\left.5 \mathrm{~h}\right)$ under dark conditions. After this heat shock pre-treatment, the seedlings were kept at $25^{\circ} \mathrm{C}$ in the dark for $6 \mathrm{~h}$ for recovery. The control seedlings were kept at $25^{\circ} \mathrm{C}$. Afterwards, the seedlings with and without heat-shock were subjected to salt stress (150 mM NaCl) and drought stress (20\% PEG-6000) in Hyponex solution and grown under the above conditions [44] for $48 \mathrm{~h}$ to test their cross-adaptation. Control plants were grown in Hyponex solution only. After treatment data were taken from the leaf samples and immediately used. The experiment was replicated three times under the same conditions.

\section{Extraction and analysis of ascorbate and glutathione} After stress treatments, mustard leaves ( $0.5 \mathrm{~g}$ fresh weight) were homogenized in $1.5 \mathrm{ml}$ ice-cold acidic extraction buffer ( $6 \%$ metaphosphoric acid containing $1 \mathrm{mM}$ EDTA) using a mortar and pestle. Homogenates were centrifuged at $11,500 \times \mathrm{g}$ for 15 $\min$ at $4^{\circ} \mathrm{C}$ and the supernatant was collected for analysis of ascorbate and glutathione as described by Hossain et al., [28].

The amount of ascorbate content in the sample was determined following the method of Huang et al., [45] with some modifications $[\mathbf{2 7}, \mathbf{2 8}]$. The supernatant was neutralized with $0.5 \mathrm{M} \mathrm{K}$-phosphate buffer ( $\mathrm{pH}$ 7.0). The AsA was assayed spectrophotometrically at $265 \mathrm{~nm}$ in $100 \mathrm{mM} \mathrm{K}$-phosphate buffer ( $\mathrm{pH}$ 5.6) with 0.5 unit of ascorbate oxidase (AO). A specific standard curve with AsA was used for quantification. The glutathione pool was assayed according to previously described methods [46] with modifications [47] utilizing 0.4 $\mathrm{ml}$ of aliquots of supernatant neutralized with $0.6 \mathrm{ml}$ of 0.5 M K-phosphate buffer ( $\mathrm{pH} 7.5$ ). Based on enzymatic recycling, glutathione is oxidized by $5,5^{\prime}$-dithio-bis (2-nitrobenzoic acid) (DTNB) and reduced by NADPH in the presence of GR, and glutathione content was evaluated by the rate of absorption changes at $412 \mathrm{~nm}$ of 2-nitro-5-thiobenzoic acid (NTB) generated from the reduction of DTNB. GSSG was determined after removal of GSH by 2-vinylpyridine derivatization. Standard curves were generated with reduced and oxidized glutathione.

\section{Enzyme extraction and assays}

Extraction of enzyme from the leaf tissues was done following our previous established methods $[27,28]$. Using a pre-cooled mortar and pestle, $0.5 \mathrm{~g}$ of leaf tissue was homogenized in 1 $\mathrm{ml}$ of $50 \mathrm{mM}$ ice-cold K-phosphate buffer ( $\mathrm{pH} \mathrm{7.0)}$ containing $100 \mathrm{mM} \mathrm{KCl}, 1 \mathrm{mM}$ ascorbate, $5 \mathrm{mM} \beta$-mercaptoethanol and $10 \%(\mathrm{w} / \mathrm{v})$ glycerol. The homogenates were centrifuged at $11,500 \times \mathrm{g}$ for $10 \mathrm{~min}$ and the supernatants were used for determination of enzyme activity. All procedures were performed at $0-4^{\circ} \mathrm{C}$.

APX (EC: 1.11.1.11) activity was assayed following the method of Nakano and Asada [48]. The reaction buffer solution contained $50 \mathrm{mM} \mathrm{K}$-phosphate buffer ( $\mathrm{pH} 7.0), 0.5 \mathrm{mM}$ AsA, $0.1 \mathrm{mM} \mathrm{H}_{2} \mathrm{O}_{2}, 0.1 \mathrm{mM}$ EDTA, and enzyme extract in a final volume of $0.7 \mathrm{ml}$. The reaction was initiated by the addition of $\mathrm{H}_{2} \mathrm{O}_{2}$ and activity was measured by observing the decrease in absorbance at $290 \mathrm{~nm}$ for 1 min using an extinction coefficient of $2.8 \mathrm{mM}^{-1} \mathrm{~cm}^{-1}$.

MDHAR (EC: 1.6.5.4) activity was determined by the method of Hossain et al., [49]. The reaction mixture contained $50 \mathrm{mM}$ Tris-HCl buffer (pH 7.5), $0.2 \mathrm{mM}$ NADPH, $2.5 \mathrm{mM}$ AsA, 0.5 units of $A O$ and enzyme solution in a final volume of $0.7 \mathrm{ml}$. The reaction was started by the addition of $A O$. The activity was calculated from the change in ascorbate at $340 \mathrm{~nm}$ for $1 \mathrm{~min}$ using an extinction co-efficient of $6.2 \mathrm{mM}^{-1} \mathrm{~cm}^{-1}$.

DHAR (EC: 1.8.5.1) activity was determined by the procedure of Nakano and Asada [48]. The reaction buffer contained 50 mM K-phosphate buffer (pH 7.0), $2.5 \mathrm{mM} \mathrm{GSH}$, and $0.1 \mathrm{mM}$ DHA. The reaction was started by adding the sample solution to the reaction buffer solution. The activity was calculated from the change in absorbance at $265 \mathrm{~nm}$ for 1 min using an extinction co-efficient of $14 \mathrm{mM}^{-1} \mathrm{~cm}^{-1}$.

GR (EC: 1.6.4.2) activity was measured by the method of Hossain et al., [28]. The reaction mixture contained $0.1 \mathrm{M}$ K-phosphate buffer (pH 7.8), 1 mM EDTA, 1 mM GSSG, 0.2 $\mathrm{mM} \mathrm{NADPH}$, and enzyme solution in a final volume of $1 \mathrm{ml}$. The reaction was initiated with GSSG and the decrease in absorbance at $340 \mathrm{~nm}$ due to NADPH oxidation was recorded for $1 \mathrm{~min}$. The activity was calculated using an extinction coefficient of $6.2 \mathrm{mM}^{-1} \mathrm{~cm}^{-1}$.

GPX (EC: 1.11.1.9) activity was measured as described by Hossain et al., [28] using $\mathrm{H}_{2} \mathrm{O}_{2}$ as a substrate. The reaction mixture consisted of $100 \mathrm{mM}$ Na-phosphate buffer (pH 7.5), 1 mM EDTA, $1 \mathrm{mM} \mathrm{NaN}_{3^{\prime}} 0.12 \mathrm{mM} \mathrm{NADPH}, 2 \mathrm{mM} \mathrm{GSH}, 1$ unit GR, $0.6 \mathrm{mM} \mathrm{H}_{2} \mathrm{O}_{2}$ and $20 \mu \mathrm{l}$ of sample solution. The reaction was started by the addition of $\mathrm{H}_{2} \mathrm{O}_{2}$. The oxidation of NADPH was recorded at $340 \mathrm{~nm}$ for $1 \mathrm{~min}$ and the activity was calculated using the extinction co-efficient of $6.62 \mathrm{mM}^{-1} \mathrm{~cm}^{-1}$.

GST (EC: 2.5.1.18) activity was measured as described by Hossain et al., [28] with some modifications (Hossain et al., 2009). The reaction mixture contained $100 \mathrm{mM}$ Tris- $\mathrm{HCl}$ buffer (pH 6.5), 1.5 mM GSH, 1 mM 1-chloro-2,4- dinitrobenzene (CDNB), and enzyme solution in a final volume of $0.7 \mathrm{ml}$. The enzyme reaction was initiated by the addition of CDNB and the increase in absorbance was measured at $340 \mathrm{~nm}$ for $1 \mathrm{~min}$. The activity was calculated using an extinction co-efficient of $9.6 \mathrm{mM}^{-1} \mathrm{~cm}^{-1}$. 


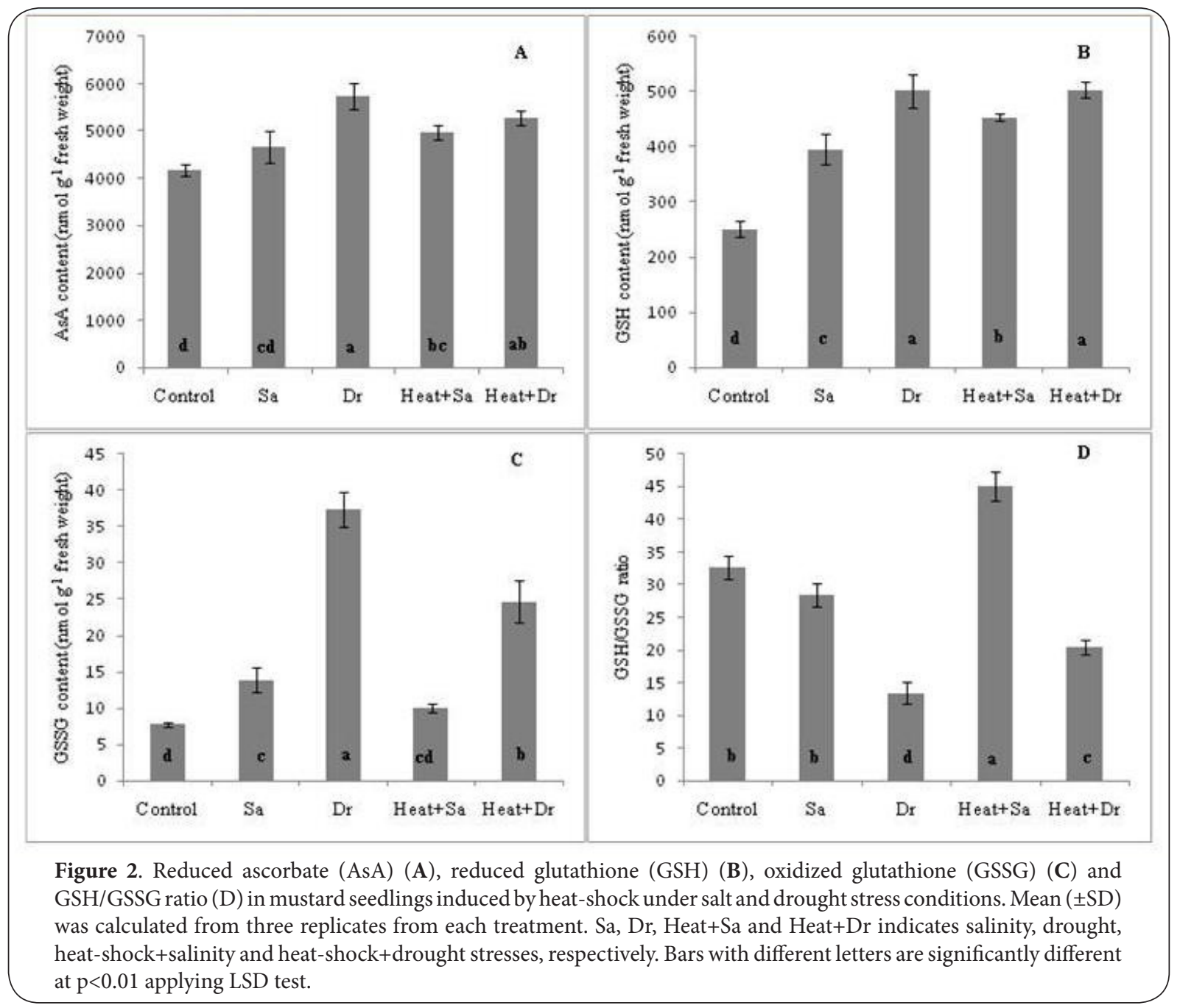

CAT (EC: 1.11.1.6) activity was measured according to the method of Hossain et al., [13] by monitoring the decrease of absorbance at $240 \mathrm{~nm}$ for $1 \mathrm{~min}$ caused by the decomposition of $\mathrm{H}_{2} \mathrm{O}_{2}$. The reaction mixture contained $50 \mathrm{mM} \mathrm{K}$-phosphate buffer ( $\mathrm{pH}$ 7.0), $15 \mathrm{mM} \mathrm{H}_{2} \mathrm{O}_{2}$ and enzyme solution in a final volume of $0.7 \mathrm{ml}$. The reaction was initiated with enzyme extract and the activity was calculated using an extinction co-efficient of $39.4 \mathrm{M}^{-1} \mathrm{~cm}^{-1}$.

Gly I (EC: 4.4.1.5) assay was carried out according to the method of Hossain et al., [13]. Briefly, the assay mixture contained $100 \mathrm{mM}$ K-phosphate buffer (pH 7.0), $15 \mathrm{mM}$ magnesium sulphate, $1.7 \mathrm{mM} \mathrm{GSH}$ and $3.5 \mathrm{mM} \mathrm{MG}$ in a final volume of $0.7 \mathrm{ml}$. The reaction was started by the addition of MG and the increase in absorbance was recorded at 240 $\mathrm{nm}$ for $1 \mathrm{~min}$. The activity was calculated using an extinction coefficient of $3.37 \mathrm{mM}^{-1} \mathrm{~cm}^{-1}$.

Gly II (EC: 3.1.2.6) activity was determined according to the method of Hossain et al., [28] by monitoring the formation of GSH at $412 \mathrm{~nm}$ for $1 \mathrm{~min}$. The reaction mixture contained $100 \mathrm{mM}$ Tris- $\mathrm{HCl}$ buffer (pH 7.2), $0.2 \mathrm{mM}$ DTNB and $1 \mathrm{mM}$
S-D-lactoylglutathione (SLG) in a final volume of $1 \mathrm{ml}$. The reaction was started by the addition of SLG and the activity was calculated using an extinction co-efficient of $13.6 \mathrm{mM}^{-1} \mathrm{~cm}^{-1}$.

\section{Measurement of hydrogen peroxide $\left(\mathrm{H}_{2} \mathrm{O}_{2}\right)$}

The level of $\mathrm{H}_{2} \mathrm{O}_{2}$ was measured in leaf tissue according to the method described by Yu et al., [50]. $\mathrm{H}_{2} \mathrm{O}_{2}$ was extracted by homogenizing $0.5 \mathrm{~g}$ of leaf tissue with $3 \mathrm{ml}$ of $50 \mathrm{mM}$ K-phosphate buffer $\mathrm{pH}(6.5)$ at $4^{\circ} \mathrm{C}$. The homogenate was centrifuged at $11,500 \times \mathrm{g}$ for $15 \mathrm{~min}$. A $3-\mathrm{ml}$ sample of supernatant was mixed with $1 \mathrm{ml}$ of $0.1 \% \mathrm{TiCl}_{4}$ in $20 \% \mathrm{H}_{2} \mathrm{SO}_{4}(\mathrm{v} / \mathrm{v})$, and the mixture was then centrifuged at $11,500 \mathrm{xg}$ for $15 \mathrm{~min}$ at room temperature. The optical absorption of the supernatant was measured spectrophotometrically at $410 \mathrm{~nm}$ to determine the $\mathrm{H}_{2} \mathrm{O}_{2}$ content $\left(\epsilon=0.28 \mu \mathrm{M}^{-1} \mathrm{~cm}^{-1}\right)$ and expressed as $\mu \mathrm{mol}$ $\mathrm{g}^{-1}$ fresh weight [28].

\section{Measurement of lipid peroxidation (MDA)}

The level of lipid peroxidation was measured in leaf tissue by estimating MDA, a decomposition product of the peroxidized 


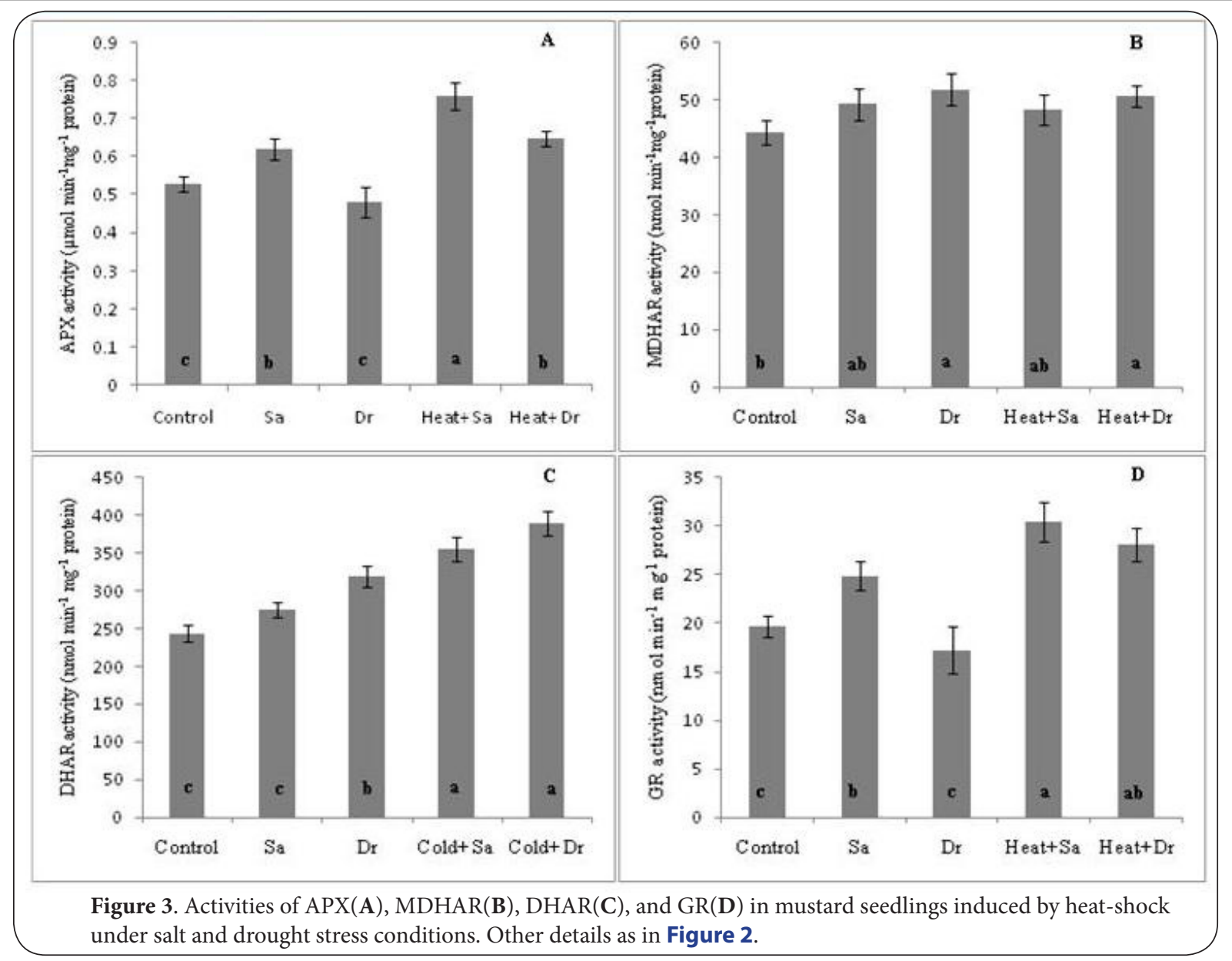

polyunsaturated fatty acid component of the membrane lipid, using thiobarbituric acid (TBA) as the reactive material following the method of Heath and Packer [51] with slight modifications [52]. The concentration of MDA was calculated by using an extinction co-efficient of $155 \mathrm{mM}^{-1} \mathrm{~cm}^{-1}$ and expressed as nmol of MDA g ${ }^{-1}$ fresh weight [28].

\section{Determination of protein}

The protein concentration of each sample was determined by the method of Bradford [53] using BSA as a protein standard.

\section{Statistical analysis}

The data obtained were analyzed by one-way analysis of variance (ANOVA) and mean differences were compared by a least significant difference (LSD) test by using MSTATC. Differences at $\mathrm{P}<0.01$ were considered to be significant.

\section{Results}

\section{Non-enzymatic antioxidant contents}

Drought stress showed a significant increase (37\%) in AsA content when compared with control (Figure 2A). Heat pretreated salt and drought-stressed seedlings also showed a significant increase ( $19 \%$ and $26 \%$ by salt and drought stress, respectively) in AsA content when compared with control.

Either salt or drought stress showed a significant increase in GSH content $(57 \%$ and $99 \%$ by salt and drought stress, respectively) when compared with control (Figure 2B). Heat pre-treated salt and drought-stressed seedlings also showed a $80 \%$ and $101 \%$ increase in GSH content when compared with control. Importantly, heat pre-treated salt-stressed seedlings showed a significant increase (15\%) in GSH content when compared with the seedlings subjected to salt stress without heat pre-treatment.

Salt stress showed a significant increase (80\%) in GSSG content but a robust increase (385\%) was observed in response to drought stress when compared with control (Figure 2C). Heat pre-treated drought-stressed seedlings showed a sharp increase (220\%) in GSSG content when compared with control. Surprisingly, heat pre-treated drought-stressed seedlings maintained significantly lower level of GSSG content (35\%) when compared with the seedlings subjected to drought stress without heat pre-treatment.

Drought stress showed a significant decrease (59\%) in GSH/GSSG ratio when compared with control (Figure 2D). 
Hossain et al. Journal of Plant Science \& Molecular Breeding 2013,

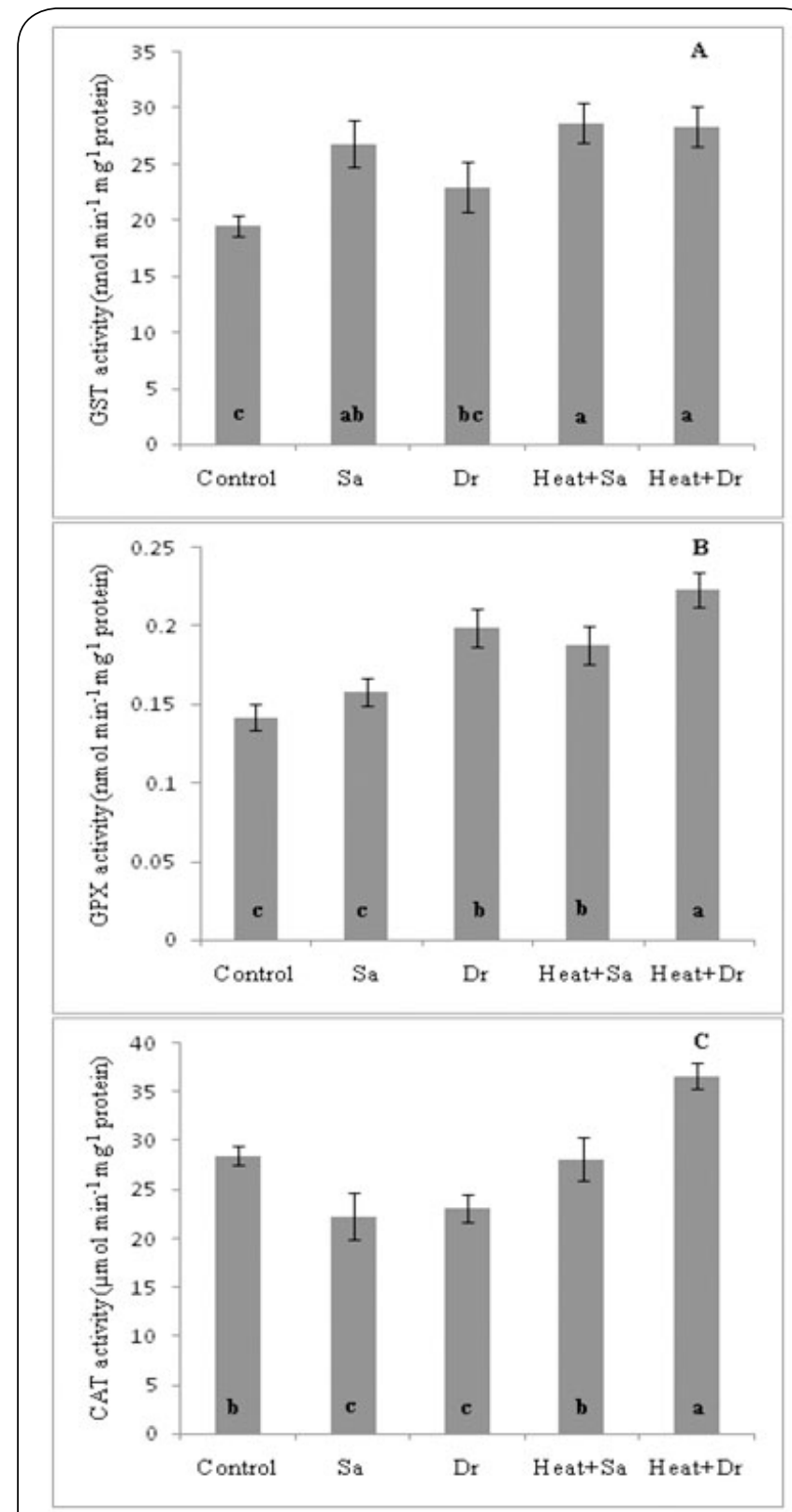

Figure 4. Activities of GST (A), GPX (B) and CAT(C) in mustard seedlings induced by heat-shock under salt and drought stress conditions. Other details as in Figure 2.

Importantly, heat pre-treated salt and drought-stressed seedlings showed a significant increase $(58 \%$ and $52 \%$ by salt and drought stress, respectively) in GSH/GSSG ratio when compared with the seedlings subjected to salt and drought stress without heat pre-treatment.

\section{Activities of antioxidant enzymes}

Salt stress showed a significant increase (17\%) in APX activity when compared with control (Figure $3 \mathrm{~A}$ ). Heat pre-treated salt and drought-stressed seedlings showed a significant increase ( $43 \%$ and $23 \%$ by salt and drought stress, respectively) in
APX activity when compared with control. Importantly, heat pre-treated salt and drought- stressed seedlings showed a significant increase ( $23 \%$ and $35 \%$ by salt and drought stress, respectively) in APX activity when compared with the seedling subjected to salt and drought stress without heat pre-treatment.

Drought stress showed a significant increase (17\%) in MDHAR activity when compared with control (Figure 3B). Heat pre-treated drought stressed seedlings also showed a significant increase (14\%) in MDHAR activity when compared with control.

Drought stress showed a significant increase (31\%) in DHAR activity when compared with control (Figure 3C). Importantly, heat pre-treated salt and drought-stressed seedlings showed a significant increase in DHAR activity $(46 \%$ and $59 \%$ by salt and drought stress, respectively) when compared with control. Heat pre-treated salt and drought-stressed seedlings maintained significantly higher DHAR activity ( $29 \%$ and $22 \%$ by salt and drought stress, respectively) when compared with the seedling subjected to salt and drought stress without heat pre-treatment.

Salt stress showed a significant increase (27\%) in GR activity when compared with control (Figure 3D). A sharp increase in GR activity ( $55 \%$ and $43 \%$ by salt and drought stress, respectively) was also observed in heat pre-treated salt and drought-stressed seedlings when compared with control. Importantly, heat pre-treated salt and drought stress seedlings showed a significant increase $(23 \%$ and $63 \%$ by salt and drought stress, respectively) when compared with the seedlings subjected to salt and drought stress without heat pre-treatment.

Salt stress showed a significant increase (38\%) in GST activity when compared with control (Figure 4A). Heat pre-treated salt and drought-stressed seedlings showed a significant increase in GST activity ( $47 \%$ and $46 \%$ by salt and drought stress, respectively) when compared with control. Importantly, heat pre-treated drought-stressed seedlings maintained a significantly higher GST activity (23\%) when compared with the seedlings subjected to salt and drought stress without heat pre-treatment.

Drought stress showed a significant increase (40\%) in GPX activity when compared with control (Figure 4B). Importantly, heat pre-treated salt and drought-stressed seedlings showed a significant increase (32\% and $62 \%$ by salt and drought stress, respectively) in GPX activity when compared with control. Heat pre-treated salt and drought stress seedlings maintain significantly higher GPX activity (19\% and $16 \%$ percent by salt and drought stresses, respectively) when compared with the seedlings subjected to salt and drought without heat pre-treatment.

Either salt or drought stress showed a significant decrease ( $22 \%$ and $19 \%$ by salt and drought stresses, respectively) in CAT activity when compared with control (Figure 4C). Heat pre-treated drought-stressed seedlings showed a significant 


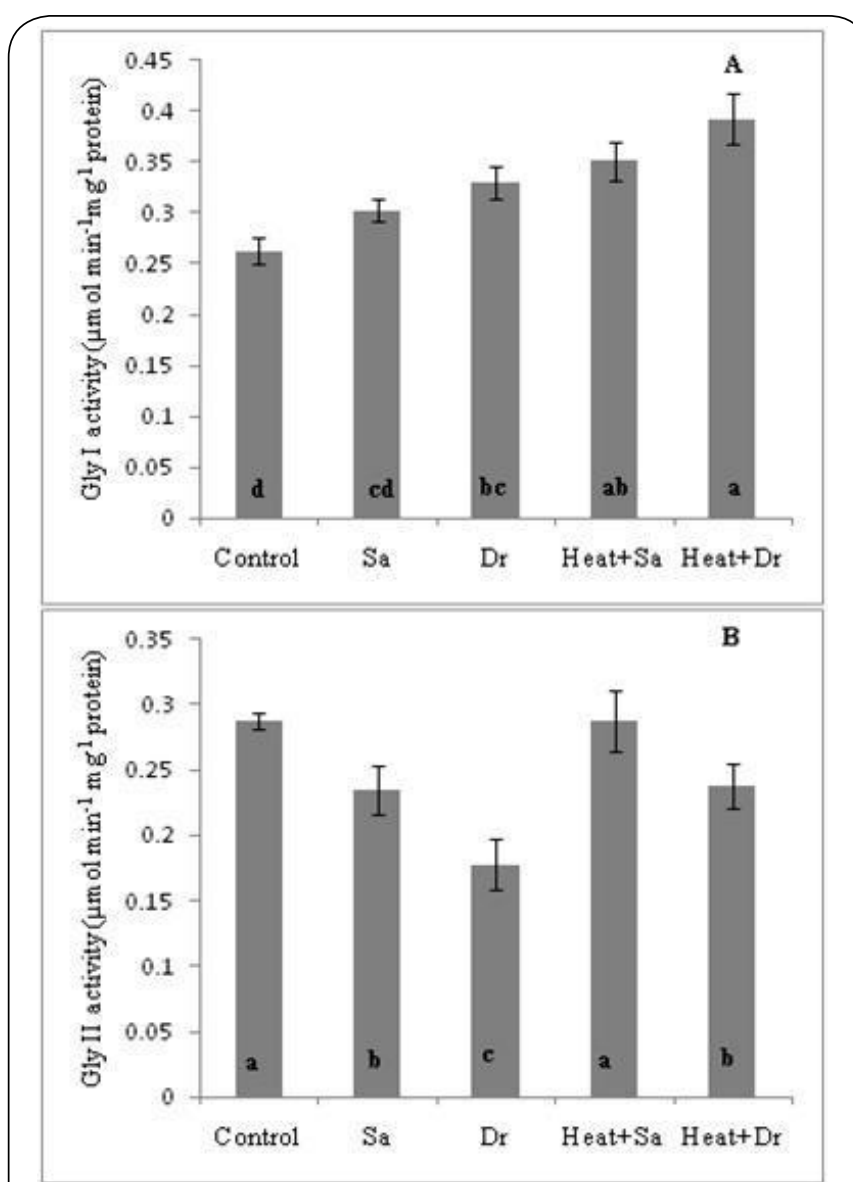

Figure 5. Activities of Gly I(A) and Gly II(B) in mustard seedlings induced by heat-shock under salt and drought stress conditions. Other details as in Figure 2.



drought stresses, respectively) when compared with the seedlings subjected to salt and drought stress without heat pre-treatment.

\section{Hydrogen peroxide $\left(\mathrm{H}_{2} \mathrm{O}_{2}\right)$ and lipid peroxidation (MDA) contents}

Either salt or drought stress showed a significant increase ( $42 \%$ and $103 \%$ by salt and drought stress, respectively) in $\mathrm{H}_{2} \mathrm{O}_{2}$ accumulation when compared with control (Figure 6A). Heat pre-treated drought-stressed seedlings also showed a $49 \%$ increase in $\mathrm{H}_{2} \mathrm{O}_{2}$ content when compared with control. Importantly, heat pre-treated salt and drought-stressed seedlings maintained significantly lower level ( $21 \%$ and $27 \%$ by salt and drought stress, respectively) of $\mathrm{H}_{2} \mathrm{O}_{2}$ content when compared with the seedlings subjected to salt and drought stresses without heat pre-treatment.

Either salt or drought stress showed a significant increase ( $46 \%$ and $105 \%$ by salt and drought stresses, respectively) in MDA content when compared with control (Figure 6B). Heat-pretreated drought-stressed seedlings also showed a significant increase (36\%) in MDA content when compared 


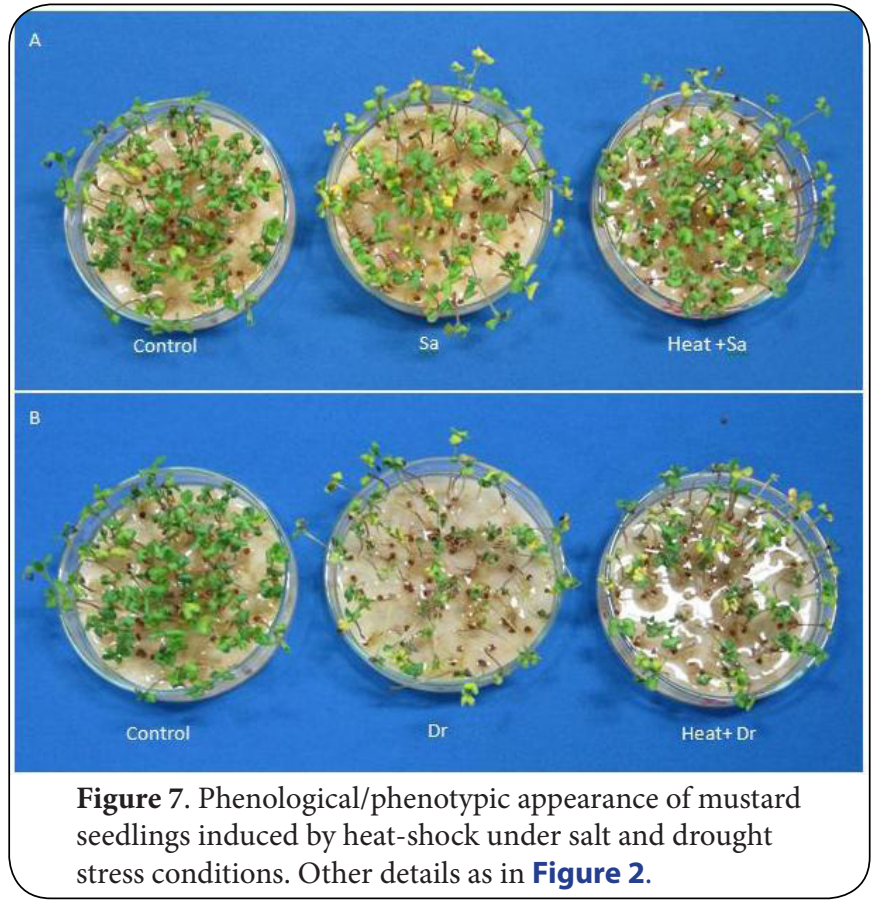

with control. Surprisingly, heat pre-treated salt and drought stressed seedlings showed a significant decrease in MDA content ( $21 \%$ and $38 \%$ by salt and drought stress, respectively) than those of the seedlings subjected to salt and drought stress without heat pre-treatment.

Phenotypic observations also showed that heat pretreated salt and drought-stressed seedlings had better visual appearance (less chlorosis/yellowing and wilting) when compared with the seedlings subjected to salt and drought stress without heat pre-treatment (Figure 7A,B).

\section{Discussion}

Acquired stress tolerance in plants is often a result of various stress-response mechanisms that act coordinately or synergistically to prevent cellular damage and to re-establish cellular homeostasis [54]. The phenomenon of cross-tolerance is extremely important for agriculture because plants can be selectively bred that are tolerant to more than one stress. Additionally, cross-tolerance allows us to compare and contrast individual responses and to examine the roles of common signal transducing molecules [55]. Cross-tolerance involves the synergistic co-activation of specific stress responsive pathways that enable a general increase in stress resistant. Numerous studies have shown that ROS exhibit important signaling functions in responses to both biotic and abiotic stresses, implying that they might be central components controlling cross-tolerance, at least at the cellular level $[33,38]$. To survive under stress conditions, it is very important that the plant antioxidant system is able to work in harmony with glyoxalase system, thus providing better defense and regeneration of the active defense forms $[7,20,56]$. Plants are capable of adapting to a wide range of temperatures by reprogramming their transcriptome, proteome and metabolome [57]. Stress adaptation through retention of imprints of previous stress exposure has recently been described in plants. Drought and salinity are the two most important abiotic stresses affecting crop yield, improving our understanding of the plant response and tolerance to these environmental challenges is a major research priority. To elucidate the biochemical mechanisms of abiotic stress tolerance in plants with special reference to ROS and MG metabolism, we previously reported osmoprotectants (proline, glycinebetaine), signalling molecule (nitric oxide) and selenium-induced abiotic stress tolerance in mung bean, rapeseed and wheat seedlings [26-29,58]. Here, we extended our understanding on biochemical mechanisms of heat-shock induced salinity and drought tolerance in mustard seedlings. We hypothesized that heat pre-treatment induces salinity and drought tolerance by balance interaction between the ROS and MG metabolism and by modulating antioxidative and glyoxalase systems.

In plants cells, ascorbic acid (AsA) is the most abundant watersoluble antioxidant and redox buffer. It serves as a cofactor for enzymes, as a regulator of cell division and growth, as well as in signal transduction [59]. AsA can directly quench ${ }^{1} \mathrm{O}_{2}, \mathrm{O}_{2}{ }^{-}$ and $\mathrm{OH}$ and regenerate a-tocopherol from a-chromanoxyl radical thereby providing protection to membranes [60]. It is the substrate of APX, which is a critical component of the AsA-GSH cycle for $\mathrm{H}_{2} \mathrm{O}_{2}$ detoxification. An increased content of AsA protects protein and lipids against oxidative damage in plants and stress tolerant varieties have higher AsA levels and AsA utilizing antioxidant enzyme activity as compared to stress-sensitive varieties [61,62]. The results of the present study reveal that salt stress slightly increased AsA content whereas a significant increase was observed in the seedlings imposed to drought stress. Recently, we reported an increase in AsA content in rapeseed seedlings in response to drought stress [44] whereas a decrease in AsA content was observed in response to salt stress in mung bean, rapeseed and wheat seedlings $[26,27,29]$. AsA level increased in a drought-tolerant rice genotype (N22) while in the susceptible genotype (N118) its level decreased [63]. However, decrease in AsA content in response to drought stresses was also reported [28,44,64-65]. Plants feeding with exogenous AsA also found to induce abiotic oxidative stress tolerance by enhancing photosynthetic capacity and protein stability and by reducing lipid peroxidation through synergic functions with other antioxidants [66-68]. In the present study, heat pre-treated salt-stressed seedlings showed a non-significant increase in AsA content, whereas, heat pretreated drought-stressed seedlings showed a non-significant decrease as compared to the seedlings subjected to salt and drought stress without pre-treatment. The phenomenon of lower level of AsA is probably due to higher APX activity in heat pre-treated salt and drought-stressed seedlings because the level of AsA under environmental stress depends on the 
balance between the rates and capacity of AsA biosynthesis and turnover related to antioxidant demand [69-70]. Our results are not consistent with the results of few recent findings where cold- and heat-hock induced chilling and heavy metal tolerance was found to be associated with higher biosynthetic capacity of AsA $[38,40]$.

Parallel to AsA, the tripeptide glutathione (GSH) is the main low molecular weight thiol in most plant tissues and plays diverse roles (Figure 1) to protect against ROS induced oxidative damage [71]. Elevated levels of GSH appear to be correlated to active plant responses to environmental stress and responses of GSH synthesis, GSH redox status, and GSH related enzyme activities (GST, GPX, Gly I, DHAR and GR) have been found repeatedly in plants under stress $[7,72,73]$. GSH accumulates in response to increased ROS or to compensate for decrease in the defense capability of other antioxidants and GSH levels are constitutively higher in plants adapted to stress conditions [74-76]. The regeneration from GSSG to GSH is catalyzed by GR and NADPH is used as the reducing power. GSH may function as a cellular sensor to ensure maintenance of the NADPH pool [77]. The property of GSH is of great biological importance since it allows fine-tuning of the cellular redox environment under normal conditions and upon onset of stress. In the present experiment, upon imposition of salt and drought stress a profuse increase in GSH content was observed in mustard seedlings (Figure 2B). Similar to our results, rapid increase in GSH content in response to salt and drought stress were also reported in mustard and rapeseed seedlings $[26,27,44,78]$. This marked increase in GSH content might be due to higher GSH biosynthesis or stimulation of GR activity $[\mathbf{4 0}, \mathbf{6 2}, \mathbf{7 8}]$. In the present experiment the significant increases in GSSG content was observed in response to both salt and drought stresses. The formation of GSSG in salt and drought-stressed seedlings might be due to the reaction of GSH with oxyradicals generated due to oxidative stress or due to enhancement of DHAR, GPX and GST activity that decompose $\mathrm{H}_{2} \mathrm{O}_{2}$ and organic hydroperoxide or insufficient increase of $\mathrm{GR}$ activity $[\mathbf{7 , 2 6 , 4 4 , 5 2 ]}$. Heat pre-treated salt-stressed seedlings maintained higher GSH level and GSH/GSSG ratio as compared to the untreated control and seedlings subjected to salt stress without heat pre-treatment, whereas, heat pre-treated drought stressed seedlings maintain significantly lower level of GSSG content and higher GSH/GSSG ratio. Therefore, heat pretreatment play a crucial role in maintaining higher GSH level either through efficient functioning of GR or by modulating higher GSH synthesis $[\mathbf{2 6 - 2 8 , 4 0 , 4 4 , 7 9 ]}$. Similar to our results heat-shock induced higher GSH biosynthesis was also reported in rice seedlings [36]. Importantly, higher accumulation of GSH is not the only factor for oxidative stress tolerance [46].

Ascorbate peroxidase is a central component of AsA-GSH cycle, and plays a pivotal role in the control of intracellular ROS levels. APX uses two molecules of AsA to reduce $\mathrm{H}_{2} \mathrm{O}_{2}$ with a concomitant generation of two molecules of MDHA. In the present study, upon imposition of salt stress APX activity increased significantly whereas a non-significant decrease was observed in response to drought stress. Increase in APX activity in response to salt stress was also reported in Brasssia juncea [80-81] and Brassica napus [26]. Similar to our results decrease in APX activity in response to drought stress was also reported in other crop species [44,82]. The decrease in APX activity in non pre-treated drought-stressed seedlings was probably due to inhibition of APX enzyme by MG [18] although the AsA content was higher. However, heat pre-treated salt and drought-stressed seedlings had higher APX activity as compared to the seedlings subjected to salt and drought stress without heat pre-treatment. Our results supported well by the few recent findings where high temperature induced modulation of APX activity induces salt and Cd tolerance of plants $[38,39]$. These results suggest that heat pre-treatment could contribute to detoxifying $\mathrm{H}_{2} \mathrm{O}_{2}$ by enhancing APX activity under salt and drought stress.

The MDHAR and DHAR are two important enzymes of AsA-GSH cycle responsible recycling of MDHA and DHA to AsA and to control its redox state under oxidative stress condition [29,83-84]. In the present experiment, both salt and drought stress increased the MHDAR and DHAR activities however greater increase in DHAR activity was observed. This indicates when one antioxidant system is inhibited then the plant exhibits another antioxidant defense system to face the adverse challenges by oxidative stress [85]. Increase in MDHAR and DHAR activities in response to salt and drought stresses were also reported [44,83,86-88]. Importantly, heat pre-treatment had no significant influence on MDHAR activity. However, the DHAR activity increased significantly in response to both salinity and drought stresses. Similar to our results crofton weed subjected to heat and drought stresses, the up regulation of DHAR activity was observed rather than MDHAR, suggesting that under these stress conditions, AsA is regenerated via GSH dependent DHAR [87]. It may be that DHAR activity could participate in AsA regeneration under conditions of severe stress when MDHAR activity is limited by the availability of NADPH [89].

Glutathione reductase which converts GSSG to GSH using NADPH is ubiquitous in living systems. It is necessary for maintaining the high ratio of GSH/GSSG ratio in the plant cells and accelerating the $\mathrm{H}_{2} \mathrm{O}_{2}$ scavenging pathway in plants particularly under stress conditions. GR plays an essential role in cell defense against reactive oxygen metabolites by sustaining the reduced status of glutathione and ascorbate poles which in turn maintain cellular redox state under stress. The adaptive behaviors of tolerant and -sensitive genotypes suggest that GR plays a significant role in maintaining the glutathione redox state under oxidative stress. Importantly, the increase of GR activity increases the ratio of NADP+/NADPH and ensures to availability of $\mathrm{NADP}^{+}$to accept electrons from the photosynthetic electron transport chain thus reducing the formation of $\mathrm{O}_{2}^{--}$which reduces the facilitation of metalcatalyzed formation of the ${ }^{\circ} \mathrm{OH}$ through the Haber-Weiss 
reaction [90-91]. Generally, stress-tolerant plants tend to have high activities of GR as compared to the sensitive plants $[63,83,92-93]$. In the current study, a significant increase in GR activity was observed in response to salt stress whereas the activity decreased under drought stress. Therefore, the decrease in GR activity was the main reason for the over accumulation of GSSG in drought-stressed seedlings which was attributed to significant decrease in GSH/GSSG ratio (Figures 2C,D and $3 C$ ). Decrease in GR activity in response to drought stress was also reported in sensitive cultivar [83]. By contrast, heat pre-treated salt and drought-stressed seedlings had higher GR activity (Figure 4C). Increased GR activity in the heat pretreated salt and drought-stressed seedlings contributes to the maintenance of higher GSH/GSSG ratio and GSH level which is used by DHAR and other GSH-dependent enzymes involved in the ROS and MG detoxification systems [7,26-28,52].

The potential role of GST isozymes has been extensively studied in plants due to its well-defined role on plant detoxification reactions [94-95]. Various abiotic stress effects are powerful inducers of GST activity in plants [96-101]. GST catalyse the binding of various xenobiotics with GSH to produce less toxic and more water-soluble conjugates [94]. Besides catalyzing the conjugation of electrophilic metabolites to GSH, GST isozymes also have peroxidase activity. A recent comprehensive study of rice GST gene expression showed its pivotal role in plant stress tolerance. Many GST genes were found to be significantly up-regulated in response to various abiotic (desiccation, salt, cold and arsenate) and biotic stresses. Surprisingly, many of the GST genes were commonly regulated by developmental processes, hormones, abiotic and biotic stresses [101]. Additionally, glutathione peroxidases are a family of isoenzymes, which catalyzes the reduction of $\mathrm{H}_{2} \mathrm{O}_{2}$ and organic peroxides, including lipid- and phospholipid hydroperoxides by using GSH [73]. Transgenic plants overexpressing GST and GPX genes also showed salt and drought stress induced oxidative stress tolerance in different crop species [102-105]. Our results showed that salt stress resulted in a significant increase in GST activity and a non-significant increase in GPX activity, whereas drought stress caused a slight increase in GST activity and a significant increase in GPX activity. Salt and drought stress-induced increase in GST and GPX activities were also reported in different plant species $[20,29,44,97]$. The modulation of GST and GPX activities in response to salt and drought stress was not sufficient to protect cells from salt and drought-induced oxidative damage. Importantly, heat pre-treatment favorably modulates the GST and GPX activities and suppressed the production of $\mathrm{H}_{2} \mathrm{O}_{2}$ and MDA level denoting that GPX and GST play important role in reducing salt and drought-induced oxidative damage.

Catalase is one of the $\mathrm{H}_{2} \mathrm{O}_{2}$ detoxifying enzymes and mostly associated with peroxisomes, where it removes $\mathrm{H}_{2} \mathrm{O}_{2}$ formed during photorespiration. Increase in CAT activity is supposed to be an adaptive trait possibly helping to overcome the damage to tissue metabolism by reducing toxic levels of $\mathrm{H}_{2} \mathrm{O}_{2}$ [92]. Our results indicated a sharp decline in CAT activity in response to both salinity and drought stresses which suggests that CAT appears not to be an effective scavenger of $\mathrm{H}_{2} \mathrm{O}_{2}$ in mustard and the increase in $\mathrm{H}_{2} \mathrm{O}_{2}$ is possibly due to the decreased

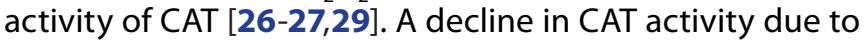
salt and drought stresses was also reported in different crop species $[44,93,106]$. Such a decrease in CAT activity could indicate its inactivation by the accumulated $\mathrm{H}_{2} \mathrm{O}_{2}$ induced by drought and salt stresses and could be partly explained by photoinactivation of enzymes [107-108]. Importantly, heat pre-treated salt and drought-stressed seedlings maintained higher CAT activity as compared to the seedlings subjected to salt and drought stresses without heat pre-treatment. Similar modulation of CAT activity by heat-shock under salt stress was also reported [39].

Glyoxalase system is an integral component of cellular detoxification of MG. The accumulation of MG in plants is rapidly increased in response to various stresses and its detoxification might be a strategy for conferring tolerance against various abiotic stresses $[13,15,17,20,28,29,52,109,110]$. A high level of MG accumulation is toxic to cells, since it inhibits cell proliferation [111] and results in a number of adverse effects such as increasing the degradation of proteins and inactivating the antioxidant defense system [17-18]. Apart from MG, pathway intermediates SLG (substrate for Gly II) has also been found to be cytotoxic at high concentrations [112]. Besides detoxification of MG, the glyoxalase system could also play a role in providing tolerance under stress by recycling GSH that would be "trapped" spontaneously by MG to form hemithioacetal, thereby maintaining glutathione homeostasis [113]. Higher Gly I and Gly II activities might protect plants against $M G$ that is formed during abiotic stresses and confers tolerance by increasing the GSH based detoxification system and decreasing lipid peroxidation $[23,25]$. Our results showed an increase in Gly I activity while the Gly II activity decreased. Salt and drought stress induced increase in Gly I activity was also found in our previous study $[13,44,110]$. By contrast, decrease in Gly II activity in response to salt and drought stresses was corroborated well with previous study $[15,20,44]$. A decrease in Gly II activity might be due to inactivation or proteolytic degradation of enzyme. Based on the results of the present study and supporting evidences from literature, we surmise that the detoxification of MG via the glyoxalase system is not sufficient under salt and drought stress conditions. In contrast, heat pre-treated seedlings could significantly alleviate the salinity and drought induced oxidative damage by maintaining higher Gly I and II activities, suggesting that both of them were able to enhance GSH regeneration via the glyoxalase system. As GSH is recycled by the glyoxalase system, it was assumed that an increased level of MG was detoxified efficiently in the heat pre-treated seedlings, thus creating the possibility of the up-regulation of GSH/GSSG ratio via the glyoxalase cycle and AsA-GSH cycle. Recently, Upadhyaya et al., [15] showed that transgenic plants overexpressing GalUR (AsA 
biosynthetic gene) induces salinity tolerance by maintaining higher activity of the ROS removing antioxidant enzymes (APX, DHAR, GR, GST, GPX, Gly I and Gly II) as well as enhanced GSH/GSSG ratio. Transgenic plants resulted in enhanced accumulation of AsA and resisted an overall increase in MG level under salinity stress, thus, reducing the MG toxicity. Concomitantly, a relatively higher GSH/GSSG ratio is also maintained in the transgenics which protects them from salinity induced oxidative stress. These parameters along with an enhanced antioxidative capacity of transgenic plants seem to confer enhanced salt stress tolerance and metabolic interaction of ROS and MG detoxification systems.

The peroxidation of lipid membrane represented by MDA is both a reflection and measure of stress induced damage at the cellular level. Its overall effects on plant cells are to decrease membrane fluidity, to increase the leakiness of membrane protein, enzymes, and ion channels. $\mathrm{H}_{2} \mathrm{O}_{2}$ at low concentrations is suggested to be involved in the signaling of many processes, however, excessive accumulation of $\mathrm{H}_{2} \mathrm{O}_{2}$ can lead to oxidative stress. It is thus the mechanism in plant to regulate the levels of $\mathrm{H}_{2} \mathrm{O}_{2}$ under salt stress rather than to remove it completely. In the current experiment salt and drought stresses significantly increased MDA and $\mathrm{H}_{2} \mathrm{O}_{2}$ levels and control of the levels of $\mathrm{H}_{2} \mathrm{O}_{2}$ and MDA is thought to be a mechanism by which plants tolerate these stresses [92]. These results corroborate well with previous reports where salinity and drought caused a sharp increase in $\mathrm{H}_{2} \mathrm{O}_{2}$ and MDA levels in different plant species including rapeseed and mustard $[28-29,44,52,114]$. A sharp increase in the levels of $\mathrm{H}_{2} \mathrm{O}_{2}$ and MDA in response to salt and drought stresses was due to insufficient antioxidant defense and MG detoxification system. Importantly, we found an active $\mathrm{H}_{2} \mathrm{O}_{2}$ peak in the leaf tissues of mustard seedlings after $5 \mathrm{~h}$ of heat-shock treatment (data not shown). However, heat-shock priming favorably modulated the MDA and $\mathrm{H}_{2} \mathrm{O}_{2}$ levels as compared to the seedling subjected to salt and drought stresses without heat pre-treatment. The biochemical results of our present experiments were well correlated with the phenotypic appearance of the seedlings (Figures 7A, B).

The results allow us to conclude that both salt and drought stresses induce a severe oxidative stress due to poor induction of $\mathrm{H}_{2} \mathrm{O}_{2}$ and MG-detoxification systems. Importantly, seedling primed with heat-shock positively modulates the activities of APX, DHAR, GR, GST, GPX, Gly I and Gly II, and maintained lower levels of GSSG, $\mathrm{H}_{2} \mathrm{O}_{2}$ and MDA as compared to the control as well as in most cases seedlings subjected to salt and drought stresses without heat-shock which indicated that heat-shock priming played a pivotal role in reducing oxidative damage. The results of this study, together with our previous results [26-29,52] and available results found in the literature $[15,20,109]$ we, therefore, concluded that synergistic coactivation of antioxidative and glyoxalase systems is essential for controlling ROS and MG levels and the damage caused by them under stress. Our results showed that a retention of the imprint of previous stress exposure (heat-shock) induces salt and drought induced oxidative stress tolerance through sustained activation of antioxidative and glyoxalase defense systems which implying that they might be the vital components inducing cross-tolerance, at least at the cellular level. However, the precise mechanisms underlying heat shock-mediated salinity and drought tolerance need to be further clarified by combining molecular, physiological and metabolic studies.

\section{Abbreviations}

AO- ascorbate oxidase; APX- ascorbate peroxidase; AsA- ascorbic acid; CAT- catalase; CDNB- 1- chloro-2, 4-dinitrobenzene; DHA- dehydroascorbate; DHAR- dehydroascorbate reductase; DTNB- 5,5'-dithio-bis (2-nitrobenzoic acid); EDTA- ethylenediaminetetraacetic acid; Gly I- glyoxalase I; Gly II- glyoxalase II; GR- glutathione reductase; GSHreduced glutathione; GSSG- oxidized glutathione; GPXglutathione peroxidase; GST- glutathione S-transferase; MDA- malondialdehyde; MDHA- monodehydroascorbate; MDHAR- monodehydroascorbate reductase; MG- methylglyoxal; NADPH- nicotinamide adenine dinucleotide phosphate; NTB- 2-nitro-5-thiobenzoic acid; PEG- polyethylene glycol; ROS- reactive oxygen species; SLG-S-D-lactoylglutathione; TBA- thiobarbituric acid; TCA- trichloroactic acid

\section{Competing interests}

The authors declare that they have no competing interests.

\section{Authors' contributions}

Mohammad Anwar Hossain participated in the design of the experiment, data collection, data analysis and manuscript preparation. Mohammad Golam Mostofa participated in the data collection and data analysis. Masayuki Fujita monitored the experimental work and critically read the manuscript. All authors read and approved the final manuscript.

\section{Acknowledgement}

Financial grant from Japan government

(Monbukagakusho) is gratefully acknowledged.

Publication history

Received: 28-Jan-2013 Revised:16-Feb-2013

Accepted: 19-Feb-2013 Published: 01-Mar-2013

\section{Reference}

1. Cominelli $E$, Conti L, Tonelli $C$ and Galbiati M: Challenges and perspectives to improve crop drought and salinity tolerance. New Biotechnol 2012. | Article | PubMed

2. Munns R: Genes and salt tolerance: bringing them together. New Phytol 2005, 167:645-63. | Article I PubMed

3. Chaves MM and Oliveira MM: Mechanisms underlying plant resilience to water deficits: prospects for water-saving agriculture. J Exp Bot 2004, 55:2365-84. | Article | PubMed

4. Xiao $\mathrm{B}$, Huang $\mathrm{Y}$, Tang $\mathrm{N}$ and Xiong L: Over-expression of a LEA gene in rice improves drought resistance under the field conditions. Theor Appl Genet 2007, 115:35-46. I Article I PubMed

5. Peng Z, Wang M, Li F, Lv H, Li C and Xia G: A proteomic study of the response to salinity and drought stress in an introgression strain of bread wheat. Mol Cell Proteomics 2009, 8:2676-86. I Article I PubMed Abstract | PubMed Full Text

6. Janska A, Marsik P, Zelenkova S and Ovesna J: Cold stress and 
acclimation - what is important for metabolic adjustment? Plant Biol 2010, 12:395-405. I Article | PubMed

7. Hossain MA, Teixeira da Silva JA and Fujita M: Glyoxalase system and reactive oxygen species detoxification system in plant abiotic stress response and tolerance: An intimate relationship. In: Shanker AK, Venkateswarlu B (Eds.) Abiotic Stress/ Book 1, INTECH-Open Access Publisher, Rijeka, Croatia, pp. 235-266. | Article

8. Kosova K, Vitamvas P, Prasil IT and Renaut J: Plant proteome changes under abiotic stress--contribution of proteomics studies to understanding plant stress response. J Proteomics 2011, 74:1301-22. | Article | PubMed

9. Hossain MA and Fujita M: (2012) Regulatory role of components of ascorbate-glutathione (AsA-GSH) pathway in plant tolerance to oxidative stress. In: Anjum NA, Umar S, Ahmed A (Eds.) Oxidative stress in plants: causes, consequences and tolerance, IK International Publishing House Pvt. Ltd., INDIA, pp. 81-147.

10. Reguera $M$, Peleg $Z$ and Blumwald E: Targeting metabolic pathways for genetic engineering abiotic stress-tolerance in crops. Biochim Biophys Acta 2012, 1819:186-94. | Article | PubMed

11. Cruz de Carvalho MH: Drought stress and reactive oxygen species: Production, scavenging and signaling. Plant Signal Behav 2008, 3:15665. | Article | PubMed Abstract | PubMed Full Text

12. Abogadallah GM: Antioxidative defense under salt stress. Plant Signal Behav 2010, 5:369-74. | Article | PubMed Abstract | PubMed Full Text

13. Hossain MA, Hossain MZ and Fujita M: Stress-induced changes of methylglyoxal level and glyoxalase $I$ activity in pumpkin seedlings and cDNA cloning of glyoxalase I gene. Aust J Crop Sci 2009, 3: 53-64. | Article I PDF

14. Banu MN, Hoque MA, Watanabe-Sugimoto M, Islam MM, Uraji M, Matsuoka K, Nakamura Y and Murata Y: Proline and glycinebetaine ameliorated $\mathrm{NaCl}$ stress via scavenging of hydrogen peroxide and methylglyoxal but not superoxide or nitric oxide in tobacco cultured cells. Biosci Biotechnol Biochem 2010, 74:2043-9. | Article | PubMed

15. Upadhyaya $C P$, Venkatesh J, Gururani MA, Asnin L, Sharma K, Ajappala $\mathrm{H}$ and Park SW: Transgenic potato overproducing L-ascorbic acid resisted an increase in methylglyoxal under salinity stress via maintaining higher reduced glutathione level and glyoxalase enzyme activity. Biotechnol Lett 2011, 33:2297-307. | Article | PubMed

16. Hossain MA, Piyatida, P, Teixeira da Silva JA and Fujita M: Molecular mechanism of heavy metal toxicity and tolerance in plants: central role of glutathione in detoxification of reactive oxygen species and methylglyoxal and in heavy metal chelation. J Bot 2012a, Article ID 872875, 37pages. | Article

17. Hoque MA, Banu MN, Nakamura Y, Shimoishi Y and Murata Y: Proline and glycinebetaine enhance antioxidant defense and methylglyoxal detoxification systems and reduce $\mathrm{NaCl}$-induced damage in cultured tobacco cells. J Plant Physiol 2008, 165:813-24. | Article | PubMed

18. Hoque MA, Uraji M, Torii A, Banu MN, Mori IC, Nakamura Y and Murata Y: Methylglyoxal inhibition of cytosolic ascorbate peroxidase from Nicotiana tabacum. J Biochem Mol Toxicol 2012, 26:315-21. | Article | PubMed

19. Saito R, Yamamoto $H$, Makino A, Sugimoto T and Miyake C: Methylglyoxal functions as Hill oxidant and stimulates the photoreduction of $\mathrm{O}_{2}$ at photosystem I: a symptom of plant diabetes. Plant Cell Environ 2011, 34:1454-64. | Article | PubMed

20. El-Shabrawi H, Kumar B, Kaul T, Reddy MK, Singla-Pareek SL and Sopory SK: Redox homeostasis, antioxidant defense, and methylglyoxal detoxification as markers for salt tolerance in Pokkali rice. Protoplasma 2010, 245:85-96. | Article | PubMed

21. Apel $\mathrm{K}$ and Hirt $\mathrm{H}$ : Reactive oxygen species: metabolism, oxidative stress, and signal transduction. Annu Rev Plant Biol 2004, 55:373-99. | Article | PubMed

22. Thornalley PJ: The glyoxalase system: new developments towards functional characterization of a metabolic pathway fundamental to biological life. Biochem J 1990, 269:1-11. | Article | PubMed Abstract | PubMed Full Text

23. Yadav SK, Singla-Pareek SL, Reddy MK and Sopory SK: Transgenic tobacco plants overexpressing glyoxalase enzymes resist an increase in methylglyoxal and maintain higher reduced glutathione levels under salinity stress. FEBS Lett 2005, 579:6265-71. | Article | PubMed

24. Singla-Pareek SL, Reddy MK and Sopory SK: Genetic engineering of the glyoxalase pathway in tobacco leads to enhanced salinity tolerance. Proc Natl Acad Sci U S A 2003, 100:14672-7. | Article | PubMed
Abstract | PubMed Full Text

25. Singla-Pareek SL, Yadav SK, Pareek A, Reddy MK and Sopory SK: Transgenic tobacco overexpressing glyoxalase pathway enzymes grow and set viable seeds in zinc-spiked soils. Plant Physiol 2006, 140:61323. | Article | PubMed Abstract | PubMed Full Text

26. Hasanuzzaman M, Hossain MA and Fujita M: Selenium-induced up-regulation of the antioxidant defense and methylglyoxal detoxification system reduces salinity-induced damage in rapeseed seedlings. Biol Trace Elem Res 2011, 143:1704-21. | Article | PubMed

27. Hasanuzzaman M, Hossain MA and Fujita M: Nitric oxide modulates antioxidant defense and the methylglyoxal detoxification system and reduces salinity-induced damage of wheat seedlings. Plant Biotechnol Rep 2011b, 5: 353-365. | Article

28. Hossain MA, Hasanuzzaman $M$ and Fujita M: Up-regulation of antioxidant and glyoxalase systems by exogenous glycinebetaine and proline in mung bean confer tolerance to cadmium stress. Physiol Mol Biol Plants 2010, 16:259-272. | Article

29. Hossain MA, Hasanuzzaman $M$ and Fujita $M$ : Coordinate induction of antioxidant defense and glyoxalase system by exogenous proline and glycinebetaine is correlated with salt tolerance in mung bean. Front Agric China 2011b, 5: 1-14. | Article

30. Hossain MA, Hossain MD, Rohman MM, Teixeira da Silva JA and Fujita $\mathrm{M}$ (2012b) Onion major compounds (flavonoids, organosulfurs) and highly expressed glutathione-related enzymes: possible physiological interaction, gene cloning and abiotic stress response. In: Aguirre CB, Jaramillo LM (Eds.) Onion consumption and health, Nova Science Publishers Inc., NY, USA. pp. 49-90. | Article | PubMed Abstract | PubMed Full Text

31. Wahid A, Gelani S, Ashraf SM and Foolad MR: Heat tolerance in plants: an overview. Environmental and Experimental Botany 2007, 61:199223. | Article

32. Al-Whaibi MH: Plant heat-shock proteins: A mini review. J King Saud Uni (Sci) 2010. I Article

33. Gong M, Chen BO, Li ZG and Guo LH: Heat-shock-induced cross adaptation to heat, chilling, drought and salt stress in maize seedlings and involvement of $\mathrm{H}_{2} \mathrm{O}_{2}$ J Plant Physiol 2001, 158:1125-1130. | Article | PubMed Abstract | PubMed Full Text

34. Volkov RA, Panchuk, II, Mullineaux PM and Schoffl F: Heat stressinduced $\mathrm{H}_{2} \mathrm{O}$ is required for effective expression of heat shock genes in Arabidopsis. Plant Mol Biol 2006, 61:733-46. | Article | PubMed

35. Hsu YT and Kao CH: Heat shock-mediated $\mathrm{H}_{2} \mathrm{O}_{2}$ accumulation and protection against $\mathrm{Cd}$ toxicity in rice seedlings. Physiol Plant 2007, 124:71-80. | Article | PDF

36. Chao YY, Hsu YT and Kao $\mathrm{CH}$ : Involvement of glutathione and heat schok- and hydrogen peroxide-induced cadmium tolerance of rice (Oryza sativa L.) seedlings. Plant Soil 2009, 318:37-45. | Article | PDF

37. Cao S, Bian X, Jiang S, Chen Z, Jian H and Sun Z: Cold treatment enhances lead resistance in Arabidopsis. Acta Physiol Plant 2010, 32: 19-25. | Article

38. Chao $\mathrm{YY}$ and $\mathrm{KaO} \mathrm{CH}$ : Heat shock-induce ascorbic acid accumulation in leaves increases cadmium tolerance of rice (Oryza sativa L.) seedlings. Plant Soil 2010, 336:39-48. | Article

39. Ferreira-Silva SL, Voigt EL, Silva EN, Maia JM, Fontenele AV and Silveira JAG: High temperature positively modulates oxidative protection in salt-stresses cashew plants. Environ Exp Bot 2011, 74:162-170. | Article

40. Ao PX, Li ZG, Fan DM and Gong M: Involvement of antioxidant defense system in chill hardening-induced chilling tolerance in Jatropha curcas seedlings. Acta Physiol Plant, 2012. | Article

41. Chou TS, Chao YY and Kao CH: Involvement of hydrogen peroxide in heat shock- and cadmium-induced expression of ascorbate peroxidase and glutathione reductase in leaves of rice seedlings. J Plant Physiol 2012, 169:478-86. | Article | PubMed

42. Laino P, Shelton D, Finnie C, De Leonardis AM, Mastrangelo AM, Svensson B, Lafiandra D and Masci S: Comparative proteome analysis of metabolic proteins from seeds of durum wheat (cv. Svevo) subjected to heat stress. Proteomics 2010, 10:2359-68. | Article | PubMed

43. Zhang $Y, X u L$, Zhu $X$, Gong $Y$, Xiang F, Sun $X$ and Liu L: Proteomic Analysis of Heat Stress Response in Leaves of Radish (Raphanus sativus L.). Plant Mol Biol Rep 2013, 31:195-203. | Article

44. Hasanuzzaman M and Fujita M: Selenium pretreatment upregulates the antioxidant defense and methylglyoxal detoxification system and 
confers enhanced tolerance to drought stress in rapeseed seedlings. Biol Trace Elem Res 2011, 143:1758-76. | Article | PubMed

45. Huang C, He W, Guo J, Chang X, Su P and Zhang L: Increased sensitivity to salt stress in an ascorbate-deficient Arabidopsis mutant. J Exp Bot 2005, 56:3041-9. | Article | PubMed

46. Yu CW, Murphy TM, Sung WW and Lin $\mathrm{CH}: \mathrm{H}_{2} \mathrm{O}_{2}$ treatment induces glutathione accumulation and chilling tolerance in mung bean. Funct Plant Biol 2002, 29:1081-1087. | Article |

47. Paradiso A, Berardino R, de Pinto M, di Toppi L S, Storelli FT and de Gara L: Increase in ascorbate-glutathione metabolism as local and precocious systemic responses induced by cadmium in durum wheat plants. Plant Cell Physiol 2008, 49: 362-374. | Article

48. Nakano $\mathrm{Y}$ and Asada $\mathrm{K}$ : Hydrogen peroxide is scavenged by ascorbatespecific peroxidase in spinach chloroplasts. Plant Cell Physiol 1981, 22:867-880. | Article

49. Hossain MA, Nakano $Y$ and Asada K: Monodehydroascorbate reductase in spinach chloroplasts and its participation in the regeneration of ascorbate for scavenging hydrogen peroxide. Plant Cell Physiol 1984, 25: 385-395. | Article

50. Yu CW, Murphy TM and Lin $\mathrm{CH}$ : Hydrogen peroxide-induces chilling tolerance in mung beans mediated thorugh $A B A$-independent glutathione accumulation. Funct Plant Biol, 2003, 30:955-963. | Article

51. Heath RL and Packer L: Photoperoxidation in isolated chloroplasts. I. Kinetics and stoichiometry of fatty acid peroxidation. Arch Biochem Biophys 1968, 125:189-98. | Article | PubMed

52. Hossain MA and Fujita M: Evidence for a role of exogenous glycinebetaine and proline in antioxidant defense and methylglyoxal detoxification systems in mung bean seedlings under salt stress. Physiol Mol Biol Plants 2010, 16:19-29. | Article

53. Bradford MM: A rapid and sensitive method for the quantitation of microgram quantities of protein utilizing the principle of protein-dye binding. Anal Biochem 1976, 72:248-54. | Article | PubMed

54. Wang W, Vinocur B, Shoseyov O and Altman A: Role of plant heatshock proteins and molecular chaperones in the abiotic stress response. Trends Plant Sci 2004, 9:244-52. | Article | PubMed

55. Bowler $\mathrm{C}$ and Fluhr $\mathrm{R}$ : The role of calcium and activated oxygens as signals for controlling cross-tolerance. Trends Plant Sci 2000, 5:241-6. | Article | PubMed

56. Tan M, Lu J, Zhang A, Hu B, Zhu X and Li W: The distribution and cooperation of antioxidant (iso)enzymes and antioxidants in different subcellular compartments in maize leaves during water stress. $J$ Plant Growth Regul, 2011, 30:255-271. | Article

57. Hua J: From freezing to scorching, transcriptional responses to temperature variations in plants. Curr Opin Plant Biol 2009, 12:568-73. | Article | PubMed

58. Hasanuzzaman M, Hossain MA and Fujita M: Exogenous selenium pretreatment protects rapeseed seedlings from cadmiuminduced oxidative stress by upregulating antioxidant defense and methylglyoxal detoxification systems. Biol Trace Elem Res 2012, 149:248-61. | Article | PubMed

59. Gallie DR: The role of L-ascorbic acid recycling in responding to environmental stress and in promoting plant growth. J Exp Bot 2013, 64:433-43. | Article | PubMed

60. Thomas CE, McLean LR, Parker RA and Ohlweiler DF: Ascorbate and phenolic antioxidant interactions in prevention of liposomal oxidation. Lipids 1992, 27:543-50. | Article | PubMed

61. Shalata A, Mittova V, Volokita M, Guy M and Tal M: Response of the cultivated tomato and its wild salt-tolerant relative Lycopersicon pennellii to salt-dependent oxidative stress: The root antioxidative system. Physiol Plant 2001, 112:487-494. | Article | PubMed

62. Mittova V, Theodoulou FL, Kiddle G, Gomez L, Volokita M, Tal M, Foyer $\mathrm{CH}$ and Guy $\mathrm{M}$ : Coordinate induction of glutathione biosynthesis and glutathione-metabolizing enzymes is correlated with salt tolerance in tomato. FEBS Lett 2003, 554:417-21. | Article | PubMed

63. Selote DS and Khanna-Chopra R: Drought-induced spikelet sterility is associated with an inefficient antioxidant defense in rice panicles. Physiol Plant 2004, 121:462-471. | Article

64. Sharma P and Dubey RS: Drought induces oxidative stress and enhances the activities of antioxidant enzymes in growing rice seedlings. Plant Growth Regul 2005, 46:209-221. | Article

65. Secenji M, Hideg E, Bebes A and Gyorgyey J: Transcriptional differences in gene families of the ascorbate-glutathione cycle in wheat during mild water deficit. Plant Cell Rep 2010, 29:37-50. | Article I PubMed

66. Shalata A and Neumann PM: Exogenous ascorbic acid (vitamin C) increases resistance to salt stress and reduces lipid peroxidation. $J$ Exp Bot 2001, 52:2207-11. | Article | PubMed

67. Athar HR, Khan A and Ashraf M: Exogenously applied ascorbic acid alleviates salt-induced oxidative stress in wheat. Environ Exp Bot 2008, 63: 224-231. | Article

68. Dehghan G, Rezazadeh L and Habibi G: Exogenous ascorbate improves antioxidant defense system and induces salinity tolerance in soybean seedlings. Acta Biol Szeged 2011, 55:261-264. I PDF

69. Chaves MM, Pereira JS, Maroco J, Rodrigues ML, Ricardo CP, Osorio ML, Carvalho I, Faria T and Pinheiro C: How plants cope with water stress in the field. Photosynthesis and growth. Ann Bot 2002, 89:907-16. | Article | PubMed

70. Song XS, Hu WH, Mao WH, Ogweno JO, Zhou YH and Yu JQ: Response of ascorbate peroxidase isoenzymes and ascorbate regeneration system to abiotic stresses in Cucumis sativus L. Plant Physiol Biochem 2005, 43:1082-8. | Article | PubMed

71. Sharma P, Jha AB, Dubey RS and Pessarakli M: Reactive oxygen speices, oxidative damage, and antioxidative defense mechanisms in plants under stressful conditions. J Bot 2012, 26 pages | Article

72. Alscher RG: Biosynthesis and antioxidant function of glutathione in plants. Physiol Plant 1989, 77,457-464. | Article

73. Foyer $\mathrm{CH}$ and Noctor $\mathrm{G}$ : Ascorbate and glutathione: the heart of the redox hub. Plant Physiol 2011, 155:2-18. | Article | PubMed Abstract | PubMed Full Text

74. Gupta AS, Alscher RG and McCune D: Response of photosynthesis and cellular antioxidants to ozone in populus leaves. Plant Physiol 1991, 96:650-5. | Article | PubMed Abstract | PubMed Full Text

75. May MJ and Leaver $\mathrm{CJ}$ : Oxidative stimulation of glutathione synthesis in Arabidopsis thaliana suspension cultures. Plant Physiol 1993, 103:621-627. | Article | PubMed Abstract | PubMed Full Text

76. Marrs KA: The functions and regulation of glutathione S-transferases in plants. Annu Rev Plant Physiol Plant Mol Biol 1996, 47:127-158. | Article I PubMed

77. May $M$, Vernoux $T$, Leaver $C$, van Montagu $M$ and Inze D: Glutathione homeostasis in plants: implications for environmental sensing and plant development. J Exp Bot 1998, 49: 649-667. | Article

78. Ruiz JM and Blumwald E: Salinity-induced glutathione synthesis in Brassica napus. Planta 2002, 214:965-9. | Article | PubMed

79. Kocsy G, Laurie R, Szalai G, Szilágyi V, Simon-Sarkadi L, Galiba G and de Ronde JA: Genetic manipulation of proline levels affects antioxidants in soybean subjected to simultaneous drought and heat stresses. Physiol Plant 2005, 124: 227-235. | Article

80. Ahmad P: Growth and antioxidant responses in mustard (Brassica juncea $\mathrm{L}$.) plants subjected to combined effect of gibberellic acid and salinity. Arc Agron Soil Sci 2009, 56:575-588. | Article |

81. Mittal S, Kumari $\mathrm{N}$ and Sharma V: Differential response of salt stress on Brassica juncea: photosynthetic performance, pigment, proline, D1 and antioxidant enzymes. Plant Physiol Biochem 2012, 54:17-26. | Article | PubMed

82. Selote DS and Khanna-Chopra R: Antioxidant response of wheat roots to drought acclimation. Protoplasma 2010, 245:153-63. | Article | PubMed

83. Sánchez-Rodíguez E, Rubio-Wilhelmi M, Cervilla LM, Blasco B, Rioa JJ, Rosales MA, Romero L and Ruiz JM: Genotypic differences in some physiological parameters symptomatic for oxidative stress under moderate drought in tomato plants. Plant Sci 2011, 178:30-40. | Article I

84. Wang Z, Xiao Y, Chen W, Tang K and Zhang L: Increased vitamin C content accompanied by an enhanced recycling pathway confers oxidative stress tolerance in Arabidopsis. J Integr Plant Biol 2010, 52:400-9. | Article | PubMed

85. Ryang SZ, Woo SY, Kwon SY, Kim SH, Lee SH, Kim KN and Lee DK: Changes of net photosynthesis, antioxidant enzyme activities, and antioxidant contents of Liriodendron tulipifera under elevated ozone. Photosynthetica 2009, 47: 19-25. | Article

86. Sumithra K, Jutur PP, Carmel BD and Reddy AR: Salinity-induced changes in two cultivars of Vigna rediata: responses of antioxidative and proline metabolism. Plant Growth Regul 2006,50: 11-22. | Article

87. Lu P, Sang WG and Ma KP: Activity of stress-related antioxidant 
enzymes in the invasive plant crofton weed (Eupatorium adenophorum). J Integr Plant Biol 2007, 49: 1555-1564. | Article | PDF

88. Gao D, Gao Q, Xu, HY, Ma F, Zhao CM and Liu JQ: Physiological responses to gradual drought stress in the diploid hybrid Pinus densata and its two parental species. Trees 2009, 23: 717-728. Article

89. Asada $\mathrm{K}$ and Takahashi M: Production and scavenging of active oxygen in photosynthesis. In: Kyle DJ, Osmond CB, Amtzen CJ(eds.). Photoinhibition 1987, pp.227-287. | Article

90. Sudhakar CL, Akshm A and Giridarakumar S: Changes in the antioxidant enzyme efficacy in two high yielding genotypes of mulberry (Morus alba L.) under $\mathrm{NaCl}$ salinity. Plant Sci 2001, 161: 613-619. | Article

91. Yang $Y$, Han C, Liu Q, Lin B and Wang J: Effect of drought and low light on growth and enzymatic antioxidant system of Picea asperata seedlings. Acta Physiol Plant 2008, 30: 433-440. | Article

92. Sekmen AH, Turkan I and Takio S: Differential responses of antioxidative enzymes and lipid peroxidation to salt stress in salttolerant Plantago maritima and salt-sensitive Plantago media. Physiol Plant 2007, 131:399-411. | Article | PubMed

93. Aghaei K, Ehsanpour AA and Komatsu S: Potato responds to salt stress by increased activity of antioxidant enzymes. J Integr Plant Biol 2009, 51:1095-103. | Article | PubMed

94. Edwards R, Dixon DP and Walbot V: Plant glutathione S-transferases: enzymes with multiple functions in sickness and in health. Trends Plant Sci 2000, 5:193-8. | Article | PubMed

95. Haluskova L, Valentovicova K, Huttova J, Mistrik I and Tamas L: Effect of abiotic stresses on glutathione peroxidase and glutathione $S$-transferase activity in barley root tips. Plant Physiol Biochem 2009, 47:1069-74. | Article | PubMed

96. Dixon DP, Cummins L, Cole DJ and Edwards R: Glutathione-mediated detoxification systems in plants. Curr Opin Plant Biol 1998, 1:258-66. I Article I PubMed

97. Hossain $\mathrm{MZ}$ and Fujita $\mathrm{M}$ : Purification of a phi-type glutathione $S$-transferase from pumpkin flowers, and molecular cloning of its cDNA. Biosci Biotechnol Biochem 2002, 66:2068-76. | Article | PubMed

98. Fujita $\mathrm{M}$ and Hossain MZ: Molecular cloning of three tau-type glutathione $S$-transferases in pumpkin (Cucurbita maxima) and their expression. Physiol Plant 2003a, 117: 85-92. | Article

99. Fujita $\mathrm{M}$ and Hossain MZ: Modulation of pumpkin glutathione S-transferases by aldehydes and related compounds. Plant Cell Physiol 2003, 44:481-90. | Article | PubMed

100. Hossain MZ, Hossain MD and Fujita M: Induction of pumpkin glutathione $S$-transferase by different stresses and its possible mechanisms. Biol Plant 2006, 50: 210-218. | Article

101. Jain M, Ghanashyam C and Bhattacharjee A: Comprehensive expression analysis suggests overlapping and specific roles of rice glutathione S-transferase genes during development and stress responses. BMC Genomics 2010, 11:73. | Article | PubMed Abstract | PubMed Full Text

102. Yoshimura K, Miyao K, Gaber A, Takeda T, Kanaboshi H, Miyasaka H and Shigeoka S: Enhancement of stress tolerance in transgenic tobacco plants overexpressing Chlamydomonas glutathione peroxidase in chloroplasts or cytosol. Plant J 2004, 37:21-33. | Article | PubMed

103. Zhao $\mathrm{F}$ and Zhang $\mathrm{H}$ : Expression of Suaeda salsa glutathione S-transferase in transgenic rice resulted in a different level of abiotic stress tolerance. J Agric Sci, 2006, 144:547-554. | Article

104. Gaber A, Oshimura KY, Yamamoto T, Yabuta Y, Takeda T, Miyasaka $\mathrm{H}, \mathrm{Nakano} \mathrm{Y}$ and Shigeoka S: Glutathione peroxidase-like protein of Synechocystis PCC 6803 confers tolerance to oxidative and environmental stresses in transgenic Arabidopsis. Physiol Plant 2006 128:251-262. | Article

105. Ji W, Zhu Y, Li Y, Yang L, Zhao X, Cai H and Bai X: Over-expression of a glutathione S-transferase gene, GsGST, from wild soybean (Glycine soja) enhances drought and salt tolerance in transgenic tobacco. Biotechnol Lett 2010, 32:1173-9. | Article | PubMed

106. Abedi $\mathrm{T}$ and Pakniyat $\mathrm{H}$ : Antioxidant enzyme changes in response to drought stress in ten cultivar of oilseed rape (Brassica napus L.). Czech J Genet Plant Breed 2010, 46:27-34. | PDF

107. Hertwig B, Streb P and Feierabend J: Light dependence of catalase synthesis and degradation in leaves and the influence of interfering stress conditions. Plant Physiol 1992, 100:1547-53. | Article | PubMed Abstract | PubMed Full Text

108. Zhang J and Kirkham MB: Drought-stress-induced changes in activities of superoxide dismutase, catalase and peroxidase in wheat species. Plant Cell Physiol 1994, 113:139-147. | Article

109. Hoque MA, Banu MN, Nakamura Y, Shimoishi $Y$ and Murata Y: Proline and glycinebetaine enhance antioxidant defense and methylglyoxal detoxification systems and reduce $\mathrm{NaCl}$-induced damage in cultured tobacco cells. J Plant Physiol 2008, 165:813-24. | Article | PubMed

110. Hossain MA and Fujita M: Purification of glyoxalase I from onion bulbs and molecular cloning of its cDNA. Biosci Biotechnol Biochem 2009, 73:2007-13. | Article | PubMed

111. Ray S, Dutta S, Halder J and Ray M: Inhibition of electron flow through complex I of the mitochondrial respiratory chain of Ehrlich ascites carcinoma cells by methylglyoxal. Biochem J 1994, 303:69-72. | Article | PubMed Abstract | PubMed Full Text

112. Thornalley PJ: Pharmacology of methylglyoxal: formation, modification of proteins and nucleic acids, and enzymatic detoxification-a role in pathogenesis and antiproliferative chemotherapy. Gen Pharmacol 1996, 27:565-73. | Article | PubMed

113. Creighton DJ, Migliorini M, Pourmotabbed T and Guha MK Optimization of efficiency in the glyoxalase pathway. Biochemistry 1988, 27:7376-84. | Article | PubMed

114. Perez-Lopez U, Robredo A, Lacuesta M, Sgherri C, Munoz-Rueda A, Navari-Izzo $F$ and Mena-Petite $A$ : The oxidative stress caused by salinity in two barley cultivars is mitigated by elevated $\mathrm{CO}_{2}$. Physiol Plant 2009, 135:29-42. | Article | PubMed

Citation:

Anwar Hossain M, Golam Mostofa M and Fujita M: Heat-shock positively modulates oxidative protection of salt and drought-stressed mustard (Brassica campestris L.) seedlings. Journal of Plant Science and Molecular Breeding 2013, 2:2. http://dx.doi.org/10.7243/2050-2389-2-2 